\title{
Switched-boost action: a phenomenon for achieving time-division- multiplexed multi-port power transfer for nanogrid applications
}

\author{
OLIVE RAY* and SANTANU MISHRA \\ Department of Electrical Engineering, Indian Institute of Technology Kanpur, Kanpur 208016, India \\ e-mail: olive@iitk.ac.in
}

MS received 8 December 2015; revised 21 September 2016; accepted 28 January 2017

\begin{abstract}
Multi-port power converter topologies are used to interface multiple terminals (source or load) using a single converter topology. In this paper, the possibility of using switch node of a power converter stage as interface to multiple output stages has been investigated. This interfacing of multiple outputs at the same switch node occurs using time-division multiplexing of the available input power. The multiplexing of input power into different ports occurs using a phenomenon that is denoted as 'switched-boost action' in the work and this concept has been illustrated using the boost converter topology. The proposed approach has been used to interface the boost-derived architectures to different types of outputs-ac, dc and isolated dc. The circuit operation has been validated using experimental results. These circuits have been proposed as possible candidates for nanogrid applications.
\end{abstract}

Keywords. Switched-boost action; time-division multiplexing; boost converter; multi-port converters.

\section{Introduction}

The widespread proliferation of low-power-rated power electronic loads in residential applications has resulted in widespread research in the area of multi-port power converter topologies. The major motivation behind research in this direction lies in the fact that reducing the number of stages may result in lower number of components, higher compactness and better coordination control of the overall system. A typical characteristic behaviour of the loads in residential system is that they can be either ac- or dc-based; e.g., the lighting loads such as CFL and LED lights require dc input supply, while motor loads require ac voltages. A cluster of such loads in a residential system may comprise a nanogrid. The power rating for the overall system lies typically within $1 \mathrm{~kW}$. The scope of the work presented here would describe power converters that can be used in nanogrid applications [1-4].

Multi-port power converter topologies reported in literature can be classified into two broad categories: isolated and non-isolated. In both of the Two cases, the nature of the outputs that can be obtained from the topologies is the same-either all are dc or ac. For example, the most common method for achieving multiple ac outputs is by using a multi-winding arrangement. For achieving multiple dc outputs, the multi-winding arrangement is followed by a conversion stage to generate dc outputs. In this context, in order to obtain dc and ac outputs simultaneously, the most

*For correspondence common approach is to use additional cascaded dc-ac stages to multi-port $\mathrm{dc}-\mathrm{dc}$ converters. The converter topologies described in this paper can be used to achieve simultaneous dc and ac outputs using a single architecture.

Within the scope of the work, multi-port power converter topologies have been studied that use the switch node voltage to interface different converter topologies. This method of interfacing has been used to generate dual dc or dc-ac (hybrid) outputs from a single system using a single architecture. The paper is organized as follows. Section 2 describes the concept of time division multiplexing and its presence within power transfer in power electronic converters. The 'switched-boost action' has been introduced in section 3. This phenomenon has been utilized to realize multi-port power conversion stages. Section 4 describes case studies concerning the proposed circuit modification. This is followed by experimental validation of the concept. Section 5 concludes the paper.

\section{Time-division multiplexing in power conversion}

The control objectives of any power electronic converter topology are achieved by exerting suitable control over a control variable [5]. This control variable may be duty ratio in the case of $d c-d c$ converter or modulation index in the case of an inverter. Since the power electronic converter operates through different switching modes within each switching interval, there exists a switching state that 
corresponds to the operation of control variable, which corresponds to the energy transfer from the input side. Figure 1 illustrates this fact using a buck converter (figure 1a), boost converter (figure 1b) and the voltage source inverter topology (figure 1c).

The buck converter (figure 1a) operates through two switching states $-S_{1, \text { buck }}$ being either 'on' or 'off'. The time duration when this switch is 'on' is decided by the duty ratio for the switch and this controls the output voltage for the buck output. As shown in the operating waveforms for the circuit in figure 1a, the input current for the buck converter topology is discontinuous, and current is drawn from the source whenever the top-switch is 'on'. The switch node voltage $v_{s n \text {,buck }}$ is equal to the input voltage during this interval. It has to be noted here that during the rest of the time period when the top switch is 'off', the voltage at the input is not required for converter operation as power is not drawn from the input side.

Figure 1b shows the boost converter topology, where the control switch $S_{1, \text { boost }}$ regulates the state variables of the converter. The gate signal $\left(G S_{1, \text { boost }}\right)$ and the corresponding switch node voltage waveform $\left(v_{s n, b o o s t}\right)$ for the boost converter have been shown in figure $1 \mathrm{~b}$. For the boost converter the input current is continuous. However, the current builds up during the switch state when the control switch is 'on'. This is the interval when energy is drawn from the source. During the remaining portion of the switching period, the stored inductor energy is discharged into the dc output.

Figure 1c shows the voltage source inverter topology. In this case, the control variable is the modulation index. For the inverter, the input current is discontinuous and the duration for which the inverter draws current from the source is proportional to its modulation index when the inverter is modulated using unipolar sine PWM control strategy. These intervals are denoted as the power intervals.

Based upon the analysis of these three cases, the following observations can be made.

\subsection{Voltage-fed converters}

1. Voltage-fed converters such as buck converter and voltage source inverter operate by drawing a discontinuous current from the source. The input voltage source is required by the converter topology only during this interval. The time duration for this interval is either duty ratio or the modulation index. This interval is denoted as the 'power interval' for the voltage-fed topologies.

2. The value of the input voltage source does not affect the operation of the voltage-fed topologies during the nonpower interval. This interval is denoted as 'zero interval'. During this interval, since the source remains isolated by the open switches from the output, its magnitude does not affect the behaviour of the circuit, and thus, it can be zero.
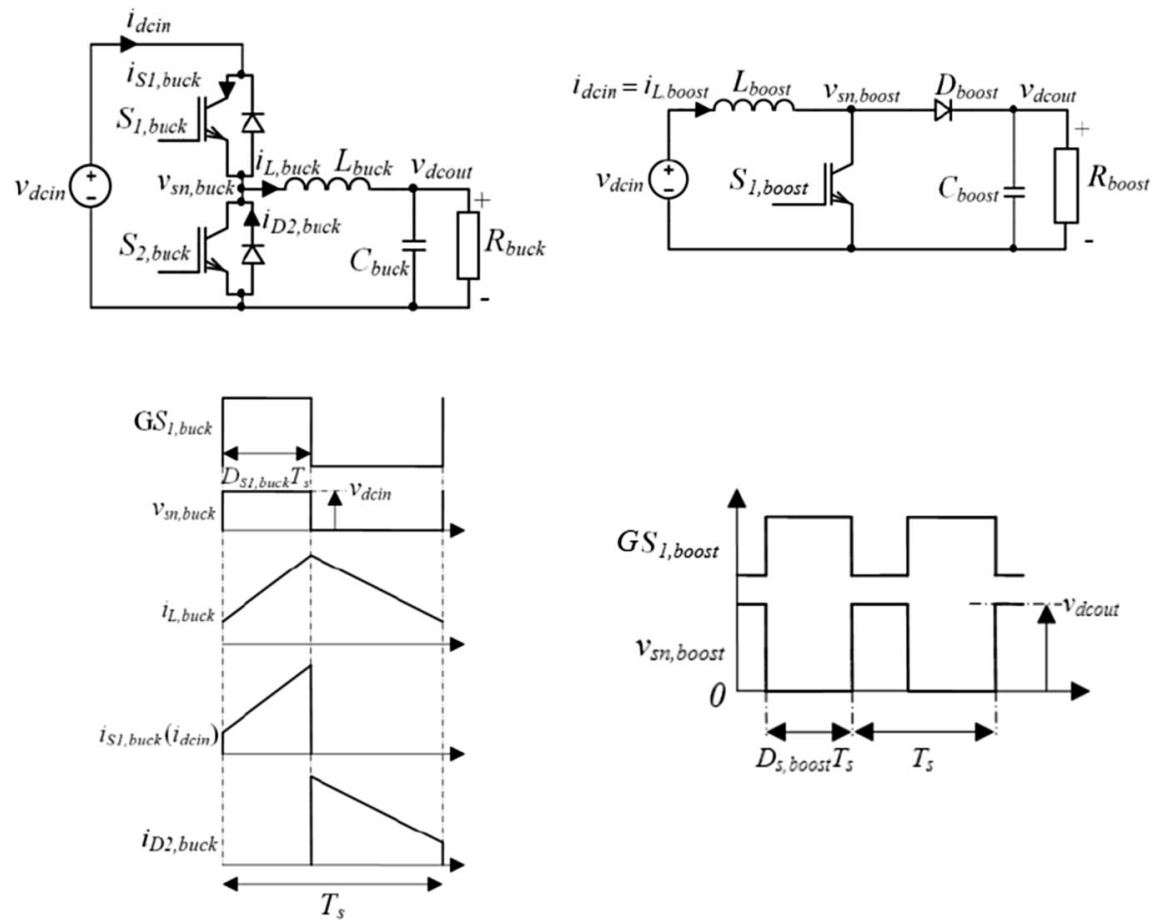

(a) (b)

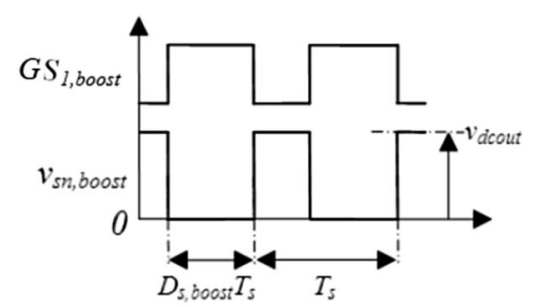

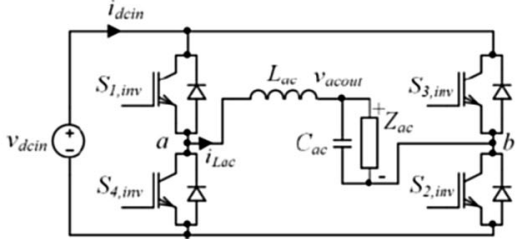

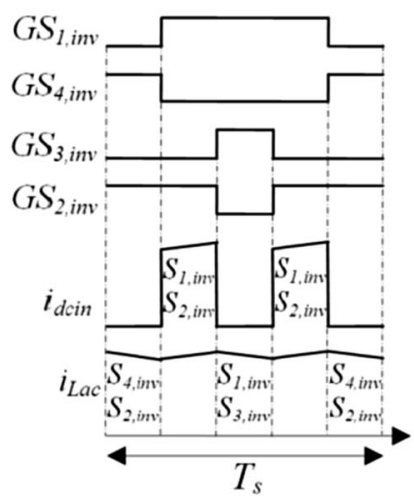

(c)

Figure 1. Power converter topologies and their relation with the control variables: (a) buck, (b) boost and (c) voltage source inverter. 
3. From the source end, the operating states of the voltagefed topologies can thus be thought of as if the input power is multiplexed into the converter during the power interval only.

\subsection{Current-fed topologies}

1. For a current-fed topology, e.g., boost converter, the power transfer operation occurs during the free-wheel period when the input power is discharged into the output end. The switch node voltage remains equal to the output voltage during this interval.

Figure 2 shows the operating regions of the controlled switches for the boost and buck converter topologies. The current and voltage reference directions are as shown in figure 1. Based upon the above observations, the concept of switched boost action will be presented in the next section.

\section{Switched-boost action}

\subsection{Scope for pulse-type dc input for voltage-fed converters}

The analysis of voltage-fed topologies indicates that the input voltage is required for converter operation during the power intervals. Since the value of the input voltage is not important for converter operation during the zero interval, a pulsed voltage waveform ( $\left.v_{\text {pulse }}\right)$ switching between the voltage values $\left\{0, V_{d c i n}\right\}$ can also be used as the input to the converter instead of having a stiff voltage source having a dc value $\left(V_{d c i n}\right)$. It has to be mentioned here that the duration of the pulse-voltage waveform in high state should be greater or equal to the power interval of the voltage-fed topologies. This has been illustrated using figure 3 for the buck converter topology.

\subsection{Boost converter switch-node as the pulsed-dc input source}

The pulse-voltage waveform can be generated by a wide variety of methods. In this work, the boost converter topology has been used to derive the pulse-voltage input source. As shown in figure $1 \mathrm{~b}$, depending upon the state of the controllable switch, the switch node voltage assumes the value of 'zero' or ' $v_{d c o u t}$ '. This switch node voltage thus has a pulsed nature and can be used as a source to the voltage-fed topologies. The concept of using the switch node of the boost converter as the input to voltage-fed topologies has been illustrated using figure 4. In this instance, the switch node voltage $v_{s n \text {,boost }}$ is used as the

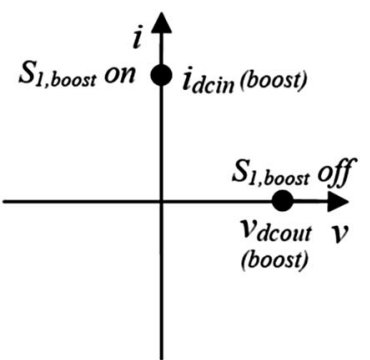

(a)

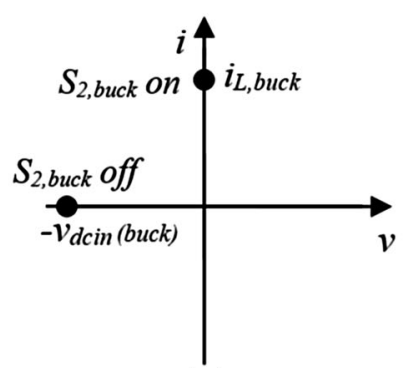

(b)

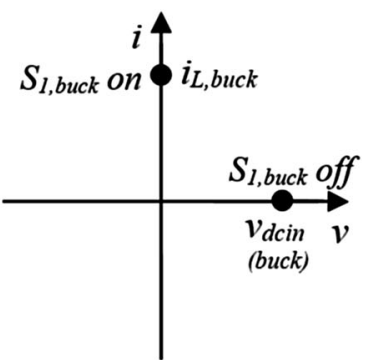

(c)

Figure 2. Switch operating regions of (a) boost and (b, c) buck converters.

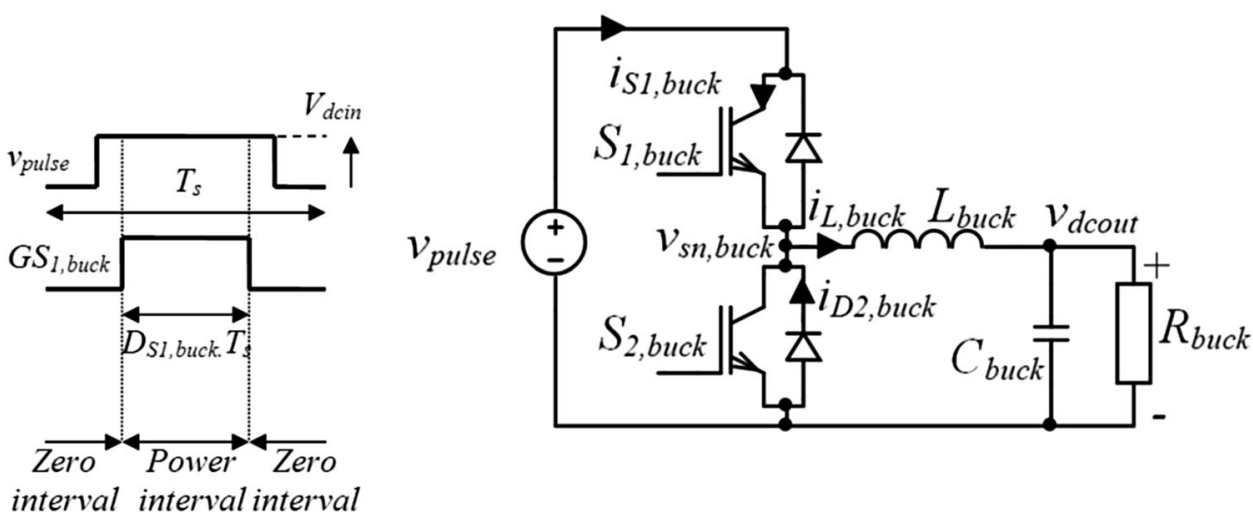

Figure 3. Pulse-voltage waveform instead of voltage-stiff dc input used for the buck topology. 


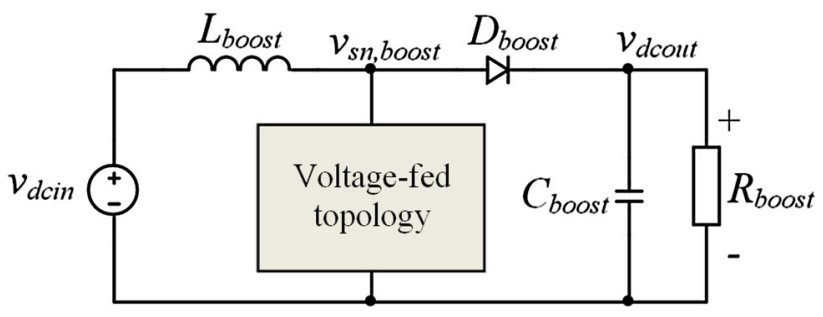

Figure 4. Switch-node voltage of boost converter used as the source for voltage-fed converter topologies.

interface to the voltage-fed topologies. Due to the use of boost topology to provide pulsed input source, the philosophy of power transfer can also be regarded as boost-converter-synchronized power transfer. Two possible configurations that have been studied in this work has been illustrated using figure 5 .

\subsection{Characteristics of switched-boost action}

The afore-mentioned phenomenon in which the switch node of a dc-dc conversion stage is used to interface voltage-fed converters is denoted as 'switched-boost action' in this work. This phenomenon allows multiplexing of power into different outputs by interfacing voltage-based topology at the switch node. A major consideration that has been made within the scope of the work is that the base converter stage always operates in continuous conduction mode (CCM) of operation. Taking the example of boost converter stage, the switched-boost action in any topology has the following characteristics.

1. Switched-boost action is a phenomenon occurring at a switch node that comprises a single-pole-double-throw (SPDT) switch associated with a current stiff element. In the case of the boost converter, the additional stage is interfaced at the switch node $\left(v_{s n, b o o s t}\right)$. Here, the input inductor current of the boost stage gets shared between the freewheeling diode current and the power interval current drawn by the interfaced circuit during the freewheeling interval. Thus the switched node is the source of the input power for the interfaced converter. The diode current appears as a notched waveform compared with that in a corresponding dc-dc stage.

2. Although the input current is supplied from the input boost inductor, the voltage across the interfaced converter is equal to the boost output voltage to which the switch node gets clamped. It has to be mentioned here that the switch node voltage should remain clamped to the output dc voltage so long as the power interval exists for the interfaced voltage-fed converter.

The following are the advantages of using switchedboost action in order to generate multi-output converters:

1. Converters based upon this principle operate using lower number of active switches compared with the separate converters. This concept would be illustrated using the case when the buck stage is interfaced to the switch node of the boost topology. The resulting topology has been shown in figure 6. Due to the circuit modification, the switches $S_{1, \text { buck }}$ and $S_{2, \text { buck }}$ are now in parallel to the switch $S_{1, \text { boost }}$, which was used to regulate the output of the boost stage only. If the operating regions of the two switches $S_{1, \text { buck }}$ and $S_{2, \text { buck }}$ encompass the operating region of the boost control switch $S_{1, b o o s t}$, the latter switch can be eliminated from the topology, resulting in the reduction in the total number of active switches. From a comparison of the switch operating regions of the switches involved in buck as well as boost converter as shown in figure 2, it can be concluded that if the two switches $S_{1, \text { buck }}$ and $S_{2, \text { buck }}$ are able to block positive

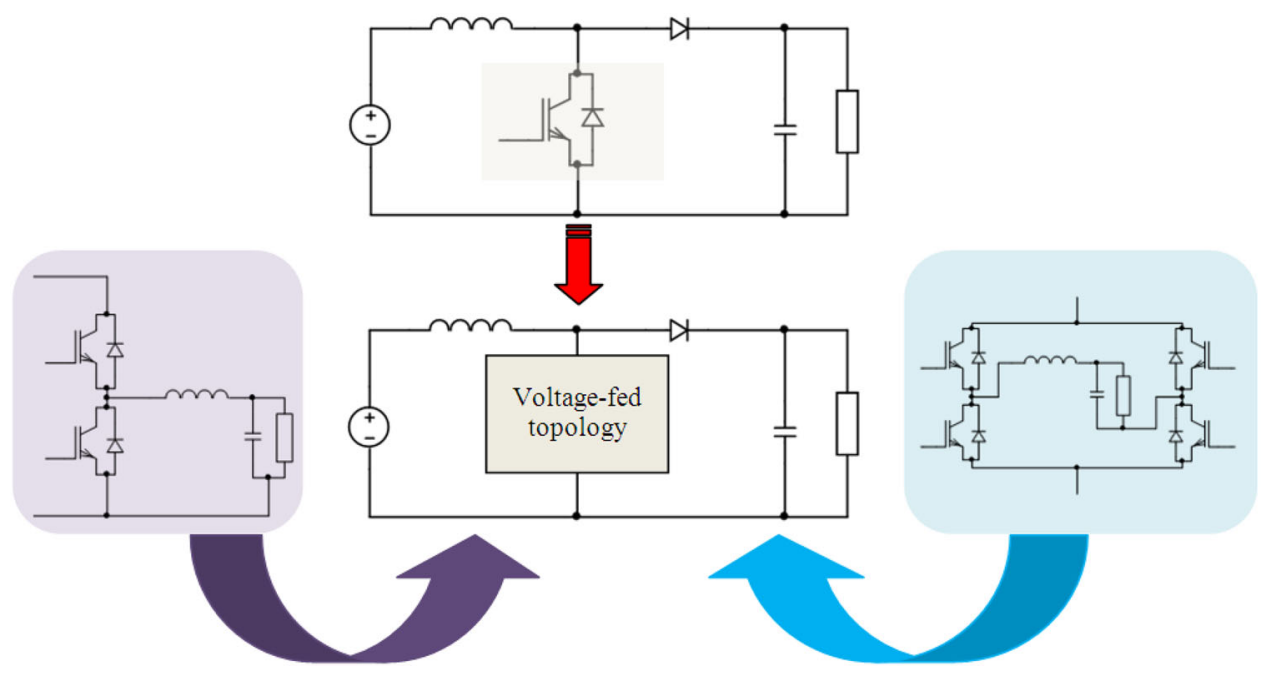

Figure 5. Voltage-fed topologies, e.g., buck converter and the voltage source inverter interfaced at the switch node of the boost converter topology. 


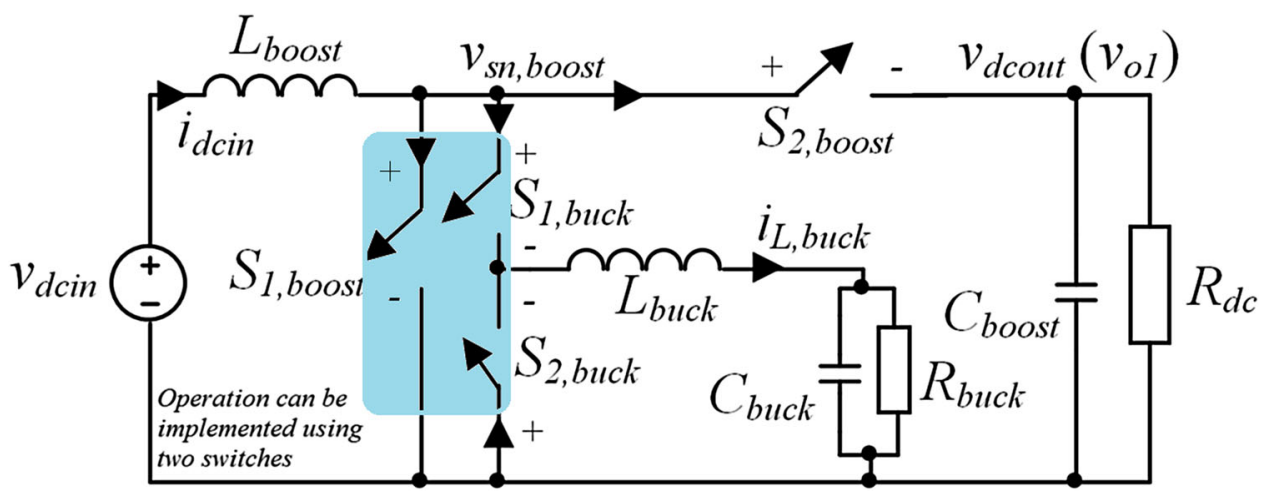

Figure 6. Integration of boost and buck converter at the switch node.

voltage and are able to conduct bidirectional current (more precisely this is required for the switch $S_{2, \text { buck }}$, note the current and voltage conventions), these specifications can be satisfied. IGBTs or mosfets with antiparallel diodes can be used for switching purpose for this topology. The resultant topology is the integrated dual output converter (IDOC), which will be described in section 4.2. Similar derivation can also be made when a voltage source inverter is interfaced to a boost converter using the same philosophy.

2. A characteristic feature of voltage-fed converters with synchronous switching is that both of the switches must have a dead-time in order to avoid shoot-through. The major reason for this is that these topologies are interfaced to a voltage-stiff source and hence protection features must be in place to prevent shorting of the

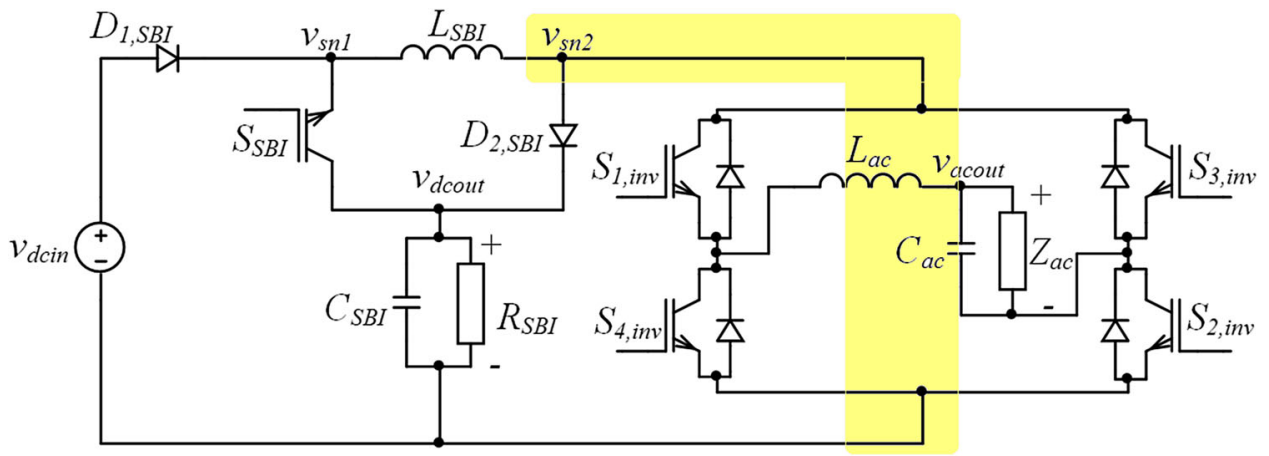

Figure 7. Switched-boost inverter topology.

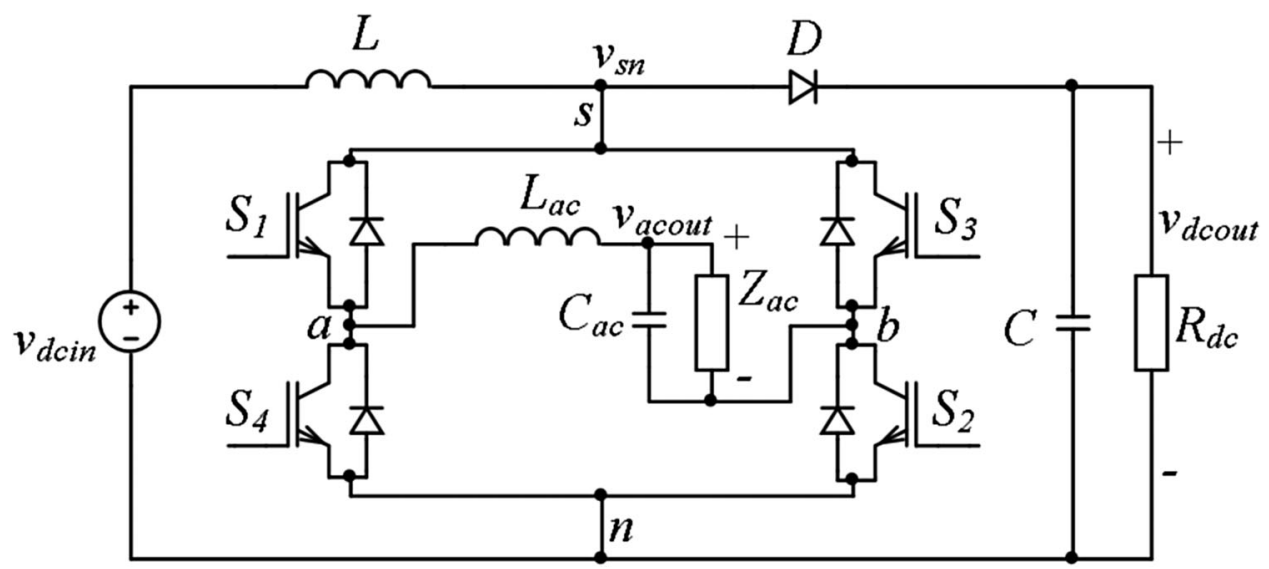

Figure 8. Boost-derived hybrid converter. 
source. In the present approach, the switch network is interfaced at the switch node and is separated by the voltage-stiff dc source by the inductor. Hence the resultant topology is inherently shoot-through-protected.

3. Since both topologies are controlled using the same set of switches, the control becomes easier. The overall system has higher power processing density.

The major operational constraints and design challenges for such converters are as follows:

1. The switched-boost action requires the switch node to be clamped to the output dc voltage during the power intervals. Hence this is a major constraint in the operation of the converter and it is reflected by having a minimum dc load at the boost output.

2. Since the total time period is shared by both the boost duty cycle and the power interval, their sum should be less than the total time period.

3. Pulse-width modulation used for conventional converters cannot be used for operation of these converters. Hence, newer PWM control strategies need to be devised for such converters.

\subsection{Higher order converter applications of switched-boost action}

The boost converter is limited in the maximum achievable gain due to the presence of non-idealities in the circuit elements. The switch nodes of higher order converter topologies can also be used for interfacing converter topologies. The advantage for this is that higher order converters have high gains. Thus, freewheel period corresponding to the step-up stage has a higher window in such cases. Figure 7 shows the switched-boost inverter [6] topology, which uses the proposed switched-boost action with the Inverse WatkinsJohnson converter topology. The shaded portion in the figure denotes the switched-boost action elements.

The next section will highlight case studies of the converter topologies derived from the boost converter and utilizing the switched-boost action. These converters are denoted as integrated power converter topologies in the work.

\section{Case studies}

\subsection{Boost-derived hybrid converter: interfacing a voltage source inverter at the switch node of the boost topology}

4.1a Overview: The boost-derived hybrid converter (BDHC) is obtained by interfacing the full-bridge inverter topology at the switch node of the boost converter topology. The converter topology, shown in figure 8 , has been studied in [7]. The operation of the converter topology requires the use of two control variables: the duty cycle $D_{S T}$ and the modulation index $m_{a}$. The inverter output is regulated using the conventional sine-PWM control strategy. However, this switching scheme needs to be incorporated within the switching strategy for the boost converter. Figure 9 shows the modification required in the PWM switching scheme for the BDHC topology. The major constituents of the PWM switching block, shown in figure 9, are the conventional unipolar sine PWM stage, boost PWM stage and the interfacing stage. The PWM scheme can provide a constant-duty cycle across all the switching intervals for boost dc output control. The PWM scheme has been studied in [8].

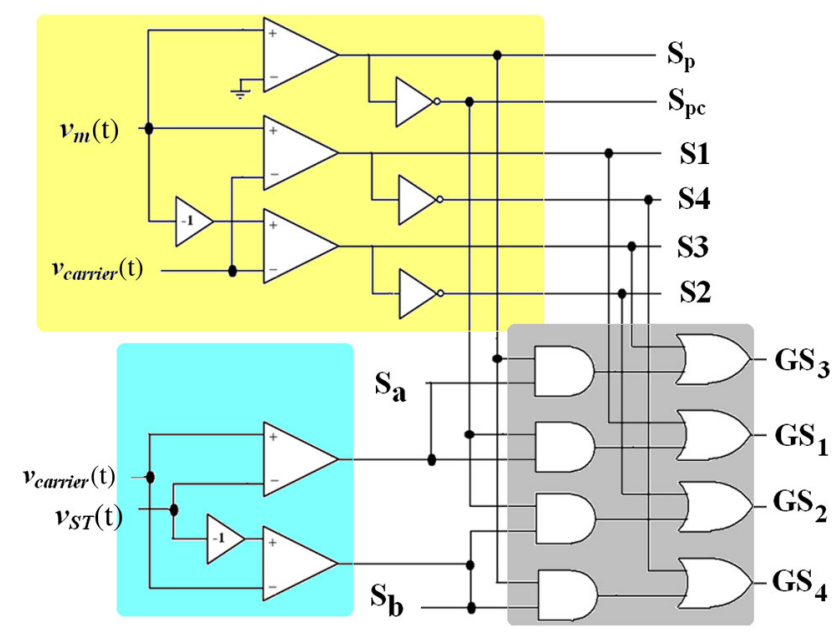

Figure 9. PWM control scheme for boost-derived hybrid converter.

Table 1. Comparison between BDHC and conventional architectures.

\begin{tabular}{lccc}
\hline & $\begin{array}{c}\text { Separate } \\
\text { boost and } \\
\text { VSI }\end{array}$ & $\begin{array}{c}\text { Boost- } \\
\text { cascaded } \\
\text { VSI }\end{array}$ & BDHC \\
\hline $\begin{array}{c}\text { Total number } \\
\text { of switches }\end{array}$ & 6 & 6 & 5 \\
$\begin{array}{c}\text { dc gain } \\
\text { Peak ac } \\
\text { voltage }\end{array}$ & $\frac{1}{1-D_{S T}}$ & $\frac{1}{1-D_{S T}}$ & $\frac{1}{1-D_{S T}}$ \\
$\begin{array}{c}\text { Range of } M_{a} \\
\text { Dead-time } \\
\text { requirement }\end{array}$ & $0 \leq M_{a} \leq 1$ & $\frac{M_{a} V_{d c i n}}{1-D_{S T}}$ & $\frac{M_{a} V_{\text {dcin }}}{1-D_{S T}}$ \\
$\begin{array}{c}\text { Control degree } \\
\text { of freedom }\end{array}$ & 2 & $M_{a} \leq 1$ & $0 \leq M_{a} \leq\left(1-D_{S T}\right)$ \\
$\begin{array}{c}\text { Control } \\
\text { elements }\end{array}$ & 5 & 2 & No \\
\hline
\end{tabular}


4.1b Operational behaviour: The BDHC is capable of providing dc and ac outputs simultaneously from a dc input. A major characteristic feature is that the gains obtained are the same as that of a separate boost converter and an inverter. The steady state dc-dc $\left(G_{d c o u t}\right)$ and dc-ac $\left(G_{\text {acout }}\right)$ gain expressions for the converter operating with a duty cycle of $D_{S T}$ and modulation index of $m_{a}$ have been shown in Eqs. (1) and (2):

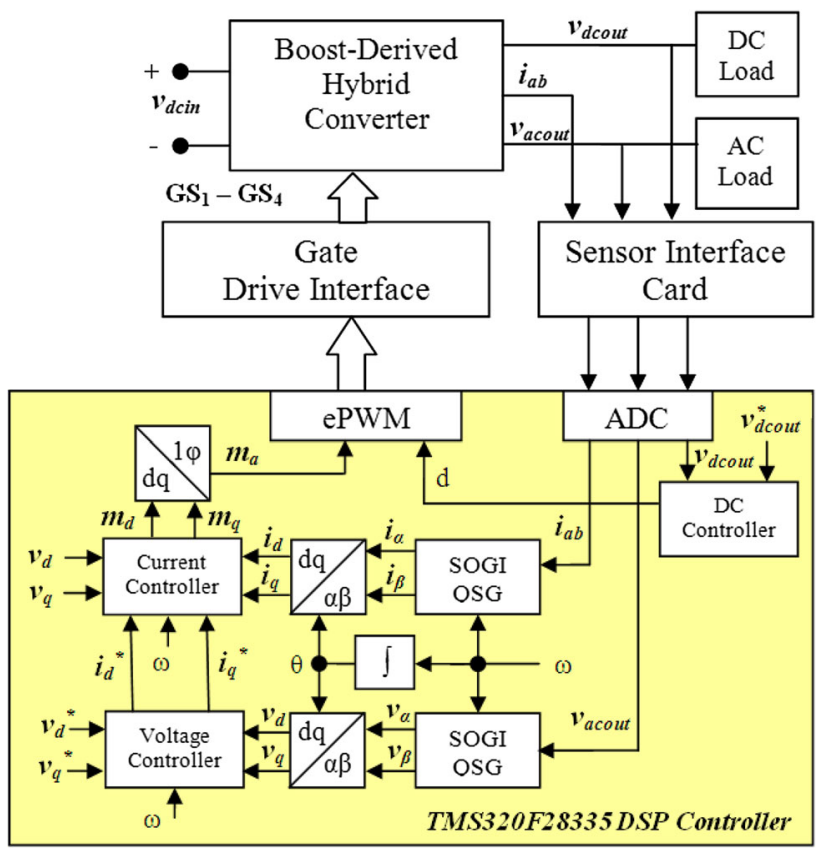

Figure 10. Closed-loop control architecture for the BDHC.

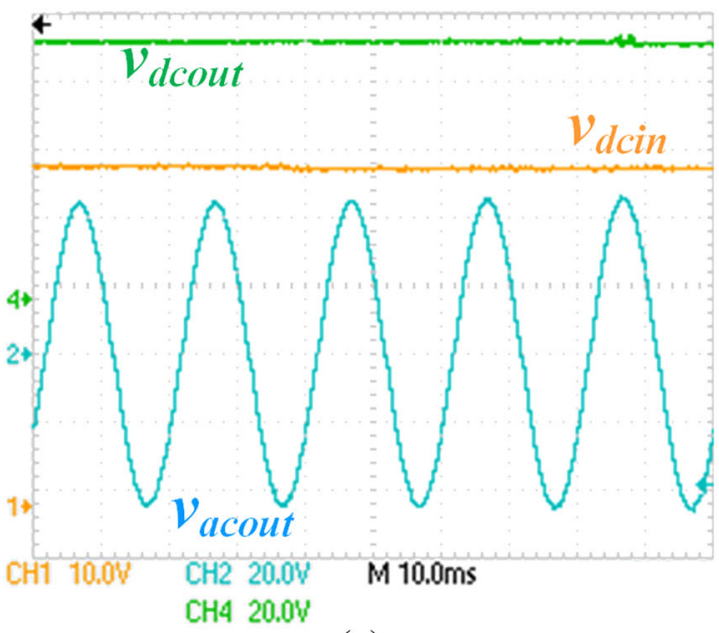

(a)

$$
\begin{gathered}
G_{d c o u t}=\frac{V_{d c o u t}}{V_{\text {dcin }}}=\frac{1}{1-D_{S T}}, \\
\hat{G}_{\text {acout }}=\frac{\hat{v}_{\text {acout }}}{V_{\text {dcin }}}=\frac{\hat{v}_{\text {acout }}}{V_{\text {dcout }}} \frac{V_{\text {dcout }}}{V_{\text {dcin }}}=\frac{M_{a}}{1-D_{S T}} .
\end{gathered}
$$

Table 1 provides a comparative analysis of the BDHC with separate boost and inverter configurations. Figure 10 shows the closed loop control system for regulating both dc and ac outputs of the BDHC. The control system for dc-dc and dc-ac stages are designed separately, as shown in the figure. The resultant control signals are interfaced at the PWM control stage using the DSP-based controller. The operating behaviour of the regulated BDHC has been shown in figure 11. Table 2 lists the parameters of the experimental prototype. Figure 11a shows the behaviour of the converter when the duty cycle of operation is 0.4 and the modulation index is 0.6. Note that the sum of duty ratio and modulation index is 1 , which is the limiting condition of the operating constraint described in the previous section. Figure $11 \mathrm{~b}$ shows the behaviour of the converter when the duty cycle is raised to 0.6 while the modulation index is 0.4 . The dc gain of the converter increases with the increase in the duty cycle, similar to a conventional boost converter. For an input dc voltage of $48 \mathrm{~V} \mathrm{dc}$, the dc output voltages of 75.4 and $108 \mathrm{~V} \mathrm{dc}$ are obtained. Since the sum of duty ratio and modulation index is the same in both the cases the ac output voltage has the same value $(30 \mathrm{~V}$ ac r.m.s.). The value is similar to what can be obtained using a single phase inverter. Figure 12 shows the closed-loop behaviour of the BDHC to load changes in either output.

4.1c Application in nanogrid scenario: The focus area behind development of integrated converter topologies in

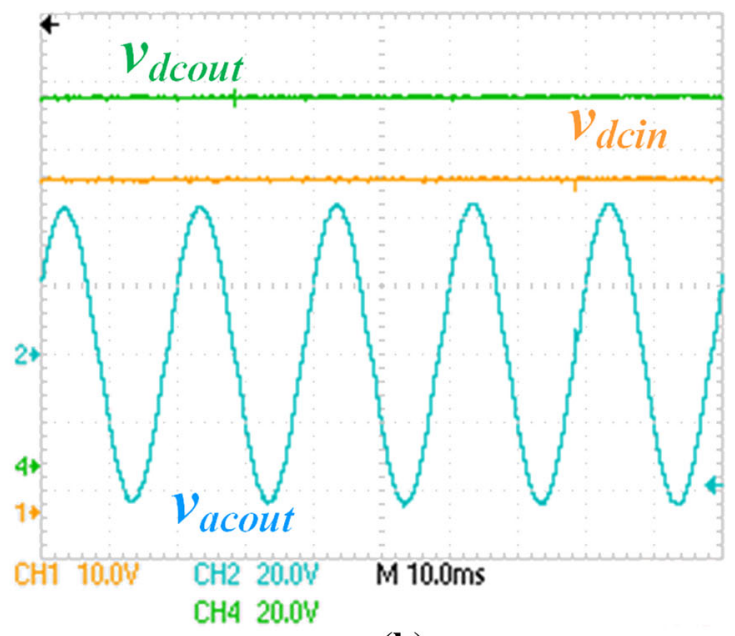

(b)

Figure 11. The BDHC produces a dc output $\left(v_{\text {dcout }}\right)$ as well as an ac output $\left(v_{\text {acout }}\right)$ from an input voltage $\left(v_{\text {dcin }}\right)$ of $48 \mathrm{~V}$ dc $(\mathrm{Ch} .1)$ : (a) dc output of $75.4 \mathrm{~V}$ (Ch. 4) and ac output of $30 \mathrm{~V}(\mathrm{rms})(\mathrm{Ch} .2)$ for $D_{S T}=0.4$ and $M_{a}=0.6$; (b) dc output of $108 \mathrm{~V} \mathrm{dc} \mathrm{(Ch.} \mathrm{4)} \mathrm{and} \mathrm{ac}$ output of $30 \mathrm{~V}$ (rms) (Ch. 2) for $D_{S T}=0.6$ and $M_{a}=0.4$. 
Table 2. Parameters of the BDHC prototype.

\begin{tabular}{lc}
\hline Component & Attributes \\
\hline Input inductor $(L)$ & $5 \mathrm{mH}$ \\
DC capacitor $(C)$ & $1 \mathrm{mF}$ \\
AC filter inductor $\left(L_{a c}\right)$ & $500 \mu \mathrm{H}$ \\
AC filter capacitor $\left(C_{a c}\right)$ & $10 \mu \mathrm{F}$ \\
\hline
\end{tabular}

this work is nanogrid applications. Figure 13 shows a typical application area of the BDHC in a nanogrid scenario [9]. A typical scenario for the afore-mentioned nanogrid is as follows: a solar panel input varying between 28 and $32 \mathrm{~V}$ dc is required to interface a dc distribution bus at $48 \mathrm{~V} \mathrm{dc}$. The system is also grid tied. In such a scenario, the power converter topology must be bidirectional in nature to interface with the grid. The interface between the solar resource and the load requires a unidirectional dc-dc stage. The BDHC with its bidirectional ac port and dual-dc ports can be used for this application. Since the voltage levels of the $d c-d c$ side are low compared with the utility-level voltages, a transformer can be used for interfacing. This also has an advantage of isolating the utility to the local system. The integrated nature of the power converter makes the control for power flow management easier.

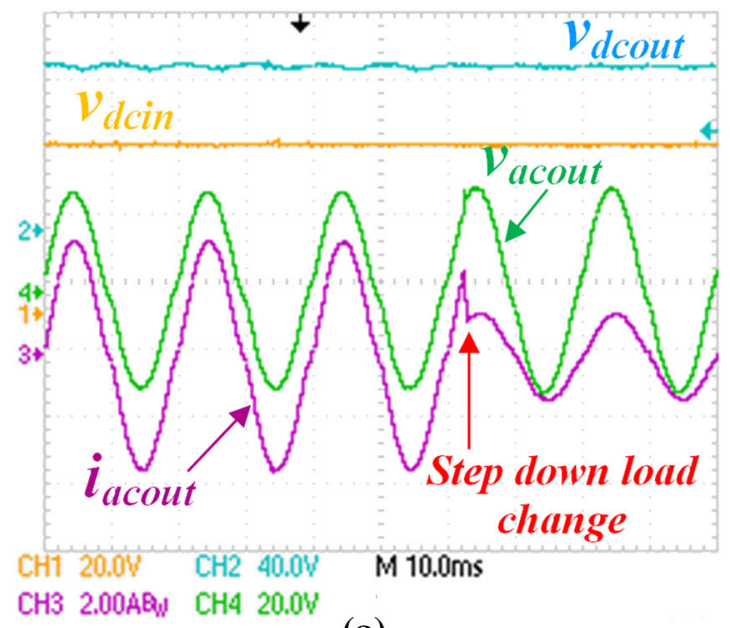

(a)

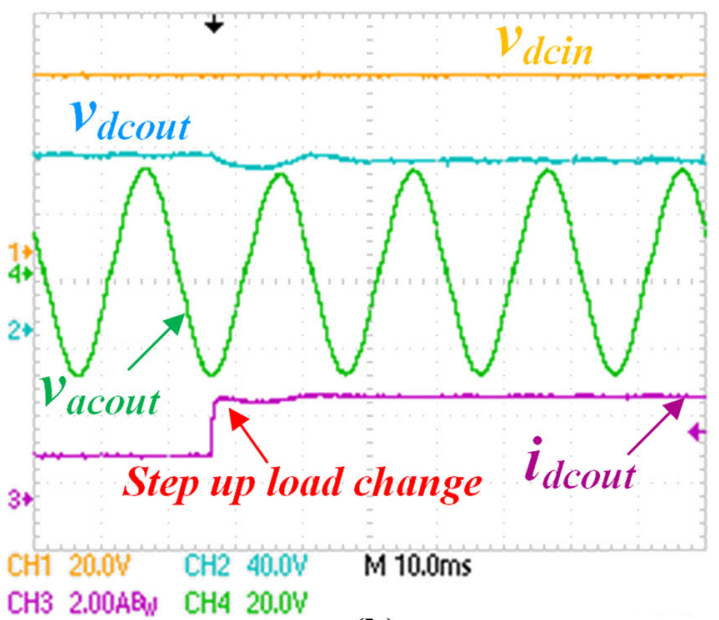

(b)

Figure 12. Step-load change behaviour of the BDHC under closed loop operation. Step change in (a) ac load and (b) de load.

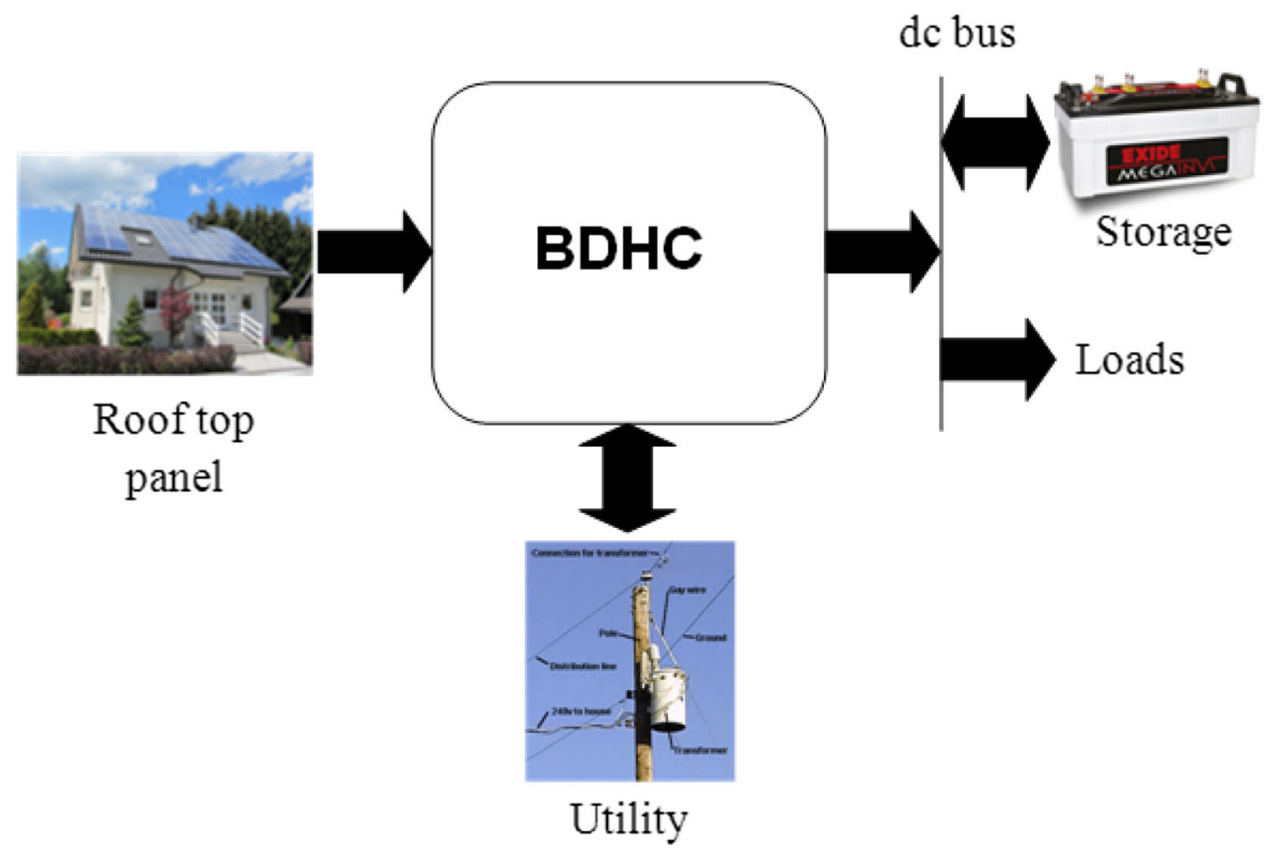

Figure 13. BDHC in a nanogrid application. 


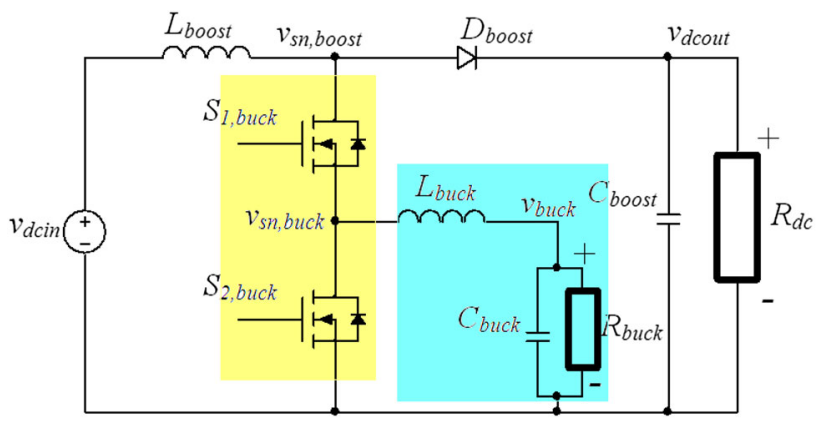

Figure 14. Integrated dual-output converter.

Table 3. Design example specifications for the IDOC.

\begin{tabular}{lc}
\hline Parameter & Attributes \\
\hline Input voltage $\left(V_{i n}\right)$ & $12 \mathrm{~V}$ \\
Step-up output voltage $\left(V_{o 1}\right)$ & $18 \mathrm{~V}$ \\
Step-down output voltage $\left(V_{o 2}\right)$ & $6 \mathrm{~V}$ \\
Step-up dc load $\left(I_{o 1}\right)$ & $5 \mathrm{~A}$ \\
Step-down dc load $\left(I_{o 2}\right)$ & $5 \mathrm{~A}$ \\
Switching frequency & $100 \mathrm{kHz}$ \\
\hline
\end{tabular}

\subsection{IDOC: interfacing a dc-dc stage at the switch node of the boost converter}

The IDOC topology is achieved by interfacing the buck converter at the switch node of the boost converter topology. A schematic of the IDOC has been shown in figure 14. The operational characteristic of the converter topology has been studied in [10]. The converter can provide a step-up and a step-down dc output from a single dc input. The steady-state expressions for the step-up $\left(G_{o 1}\right)$ and step-down $\left(G_{o 1}\right)$ gains achieved as a function of the duty ratios have been given in Eqs. (3) and (4). Here, $D_{1}$ and $D_{2}$ are the duty ratios for the bottom and top switches, respectively.

$$
\begin{gathered}
G_{o 1}=\frac{V_{o 1}}{V_{i n}}=\frac{1}{\left(1-D_{1}\right)}, \\
G_{o 2}=\frac{V_{o 2}}{V_{i n}}=\frac{V_{o 2}}{V_{o 1}} \frac{V_{o 1}}{V_{i n}}=\frac{D_{2}}{\left(1-D_{1}\right)} .
\end{gathered}
$$

The ranges of output voltages that can be achieved are the same as those of a conventional buck and a boost converter. As described in [10], during CCM operation, the IDOC operates through three distinct switching intervals. Table 3 shows the specifications for the experimental prototype used for validation of the operational characteristics of the IDOC.

Figure 15 shows an analog closed loop control system for regulating both the outputs of the IDOC. The parameters of the circuit have been listed in table 4 . Figure 16 shows the steady-state operating behaviour of the IDOC. From a $12 \mathrm{~V} \mathrm{dc}$ input, the dc outputs of 18 and $6 \mathrm{~V}$ dc are

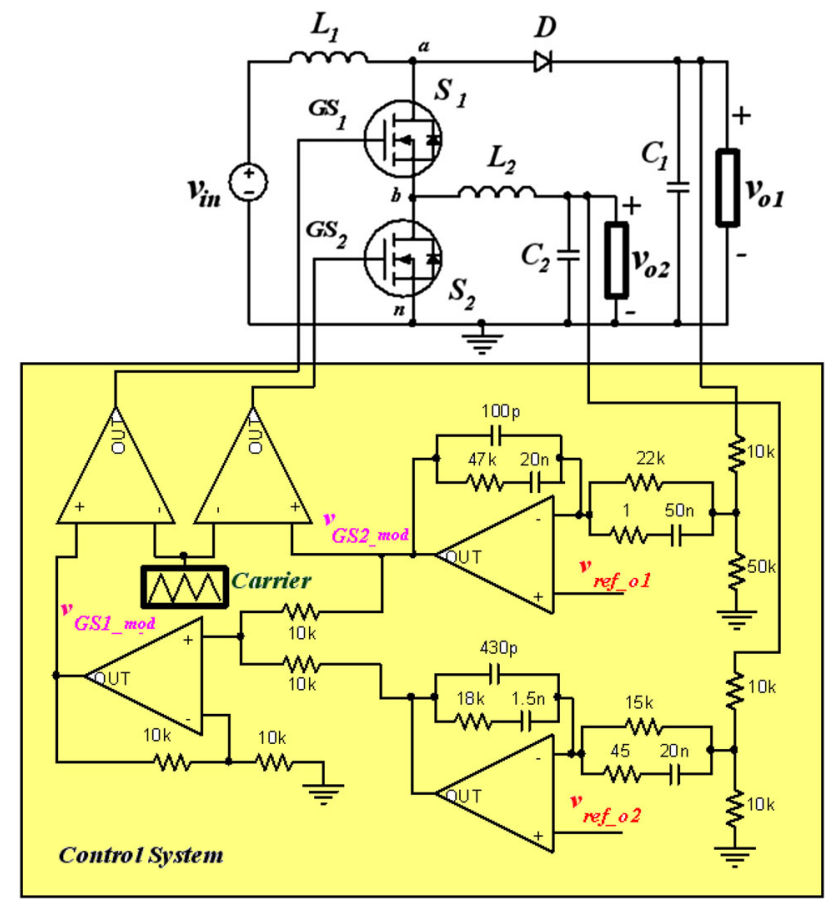

Figure 15. Control system schematic for a regulated IDOC.

Table 4. Parameters of the IDOC.

\begin{tabular}{lc}
\hline Component & Attributes \\
\hline Inductor $\left(L_{1}\right)$ & $15 \mu \mathrm{H}, \mathrm{DCR}=2.6 \mathrm{~m} \Omega, 20 \mathrm{~A}$ \\
Inductor $\left(L_{2}\right)$ & $10 \mu \mathrm{H}, \mathrm{DCR}=2.3 \mathrm{~m} \Omega, 19 \mathrm{~A}$ \\
Capacitor $\left(C_{1}\right)$ & $550 \mu \mathrm{F}$ (electrolytic) and $200 \mu \mathrm{F}$ (ceramic) \\
ESR $=50 \mathrm{~m} \Omega$ \\
Capacitor $\left(C_{2}\right)$ & $220 \mu \mathrm{F}$ (electrolytic) and $400 \mu \mathrm{F}$ (ceramic) \\
& $\mathrm{ESR}=50 \mathrm{~m} \Omega$ \\
\hline
\end{tabular}

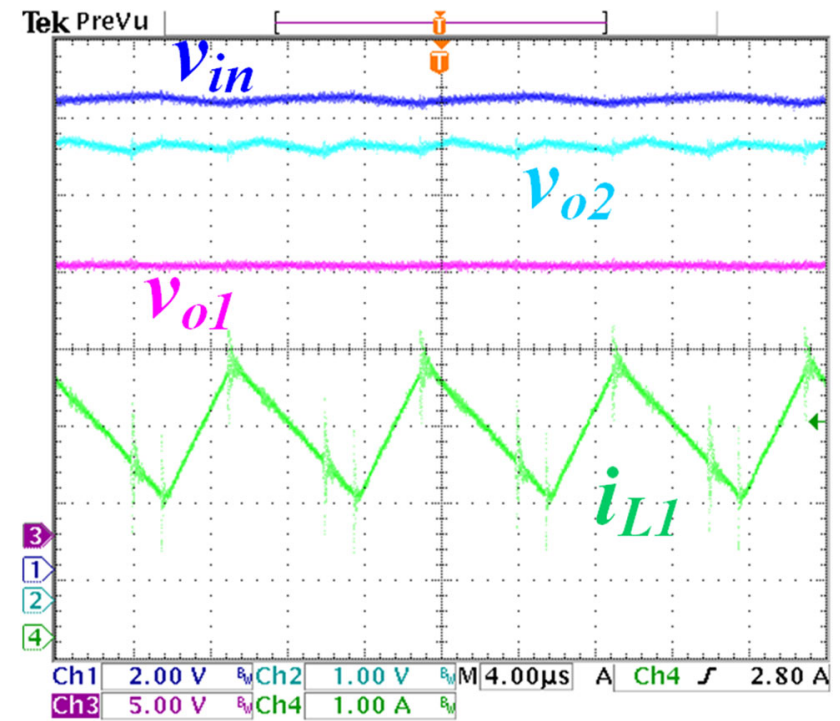

Figure 16. Verification of steady-state behaviour of IDOC. Input voltage $v_{\text {in }}$ (Ch. 1), inductor current $i_{L 1}$ (Ch. 4), step-up $v_{o 1}$ (Ch. 3) and step-down $v_{o 2}$ (Ch. 2) voltages for $D_{1}=D_{2}=0.33$. 


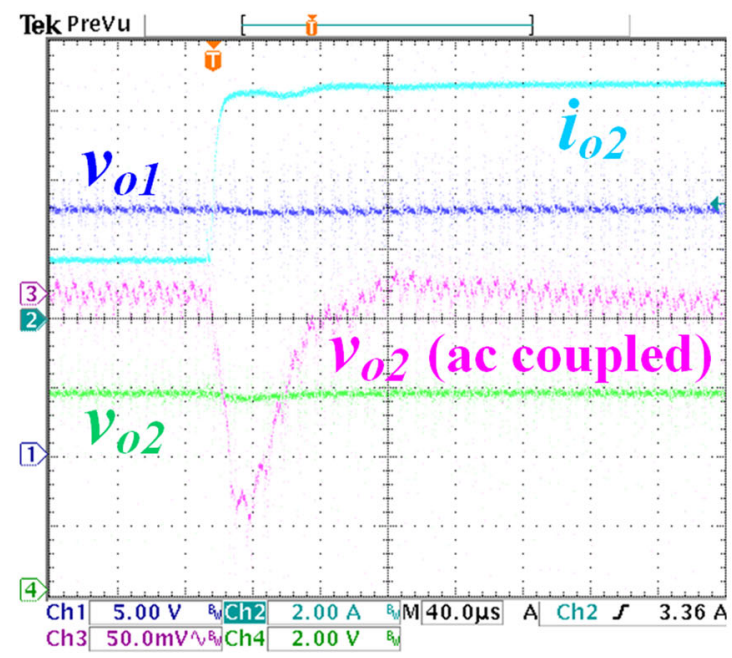

(a)

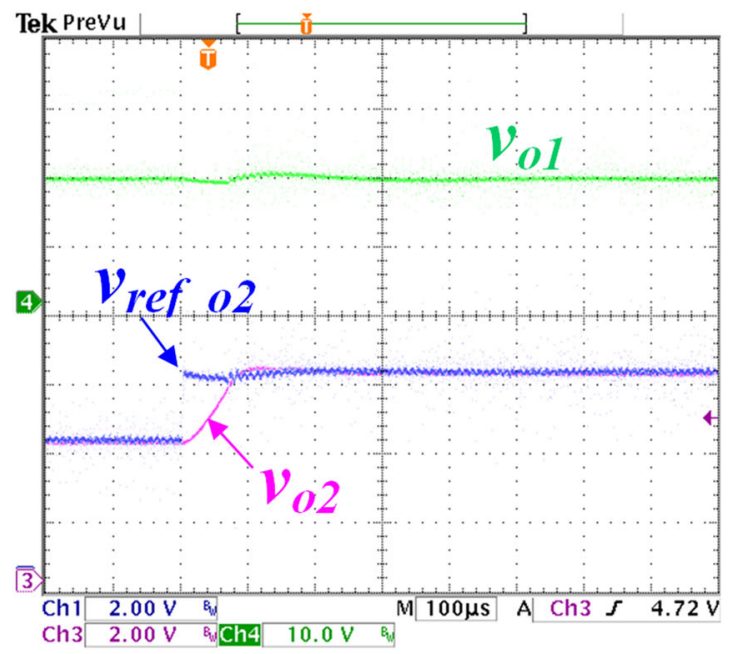

(b)

Figure 17. Verification of controller behaviour of IDOC. (a) Cross-regulation: for a 5-A step change in the step-down load, both the output voltages are well regulated. (b) Reference change: the step-up output voltage is regulated to its desired value even when there is a $2-\mathrm{V}$ change of set-point in the step-down output.

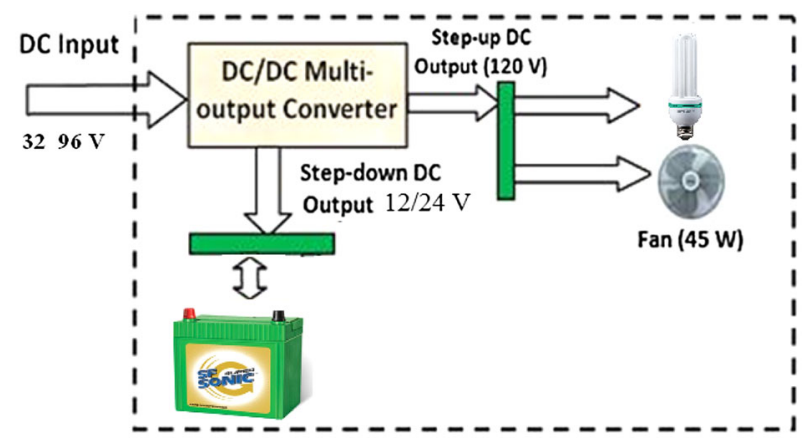

Figure 18. Integrated dual-output converter in a nanogrid scenario.

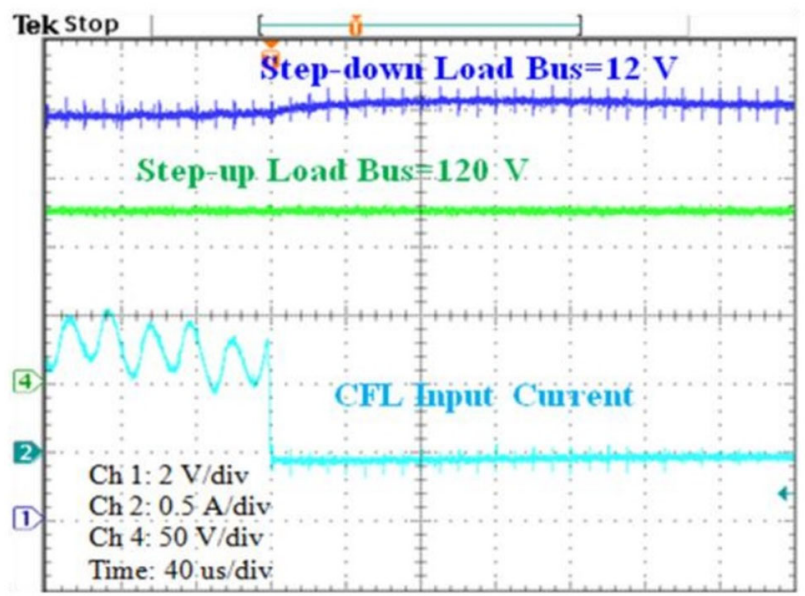

Figure 19. Dynamic behaviour of the IDOC when a CFL lamp load is turned off with other loads present.

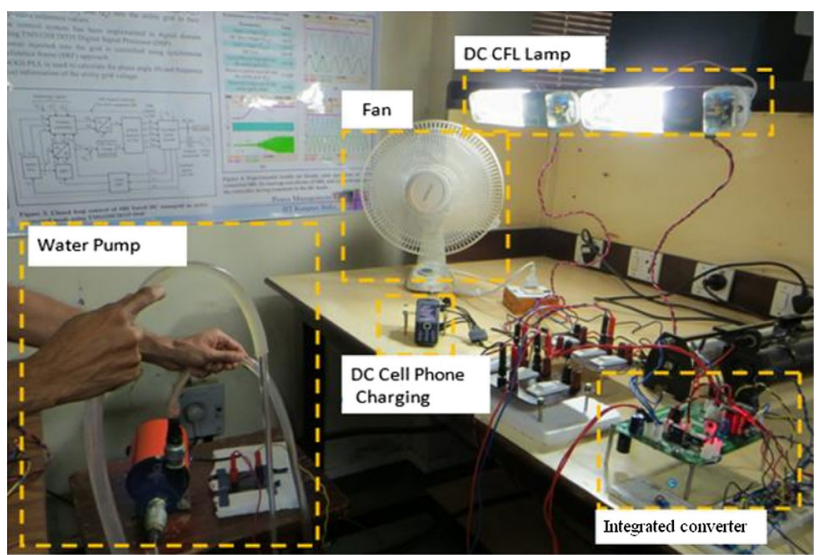

Figure 20. A rural nanogrid prototype with typical loads in operation.

obtained for duty cycles of 0.33 and 0.33 , respectively. It has to be mentioned here that there are two control variables denoted by the duty cycles for control of each of the outputs. The two outputs of the IDOC are regulated with the help of two separate voltage-mode controllers in order to regulate the outputs to their predefined set-points. The controller design in this case is similar to the design of buck and boost topology; the only difference here is how the two duty cycles are generated. Figure 17a shows that when the step-down port of the IDOC is subjected to a step-up load change of $5 \mathrm{~A}$, the implemented control system shown in figure 15 can precisely regulate both the outputs to their predetermined values. The step-down output voltage settles to its set-point in about $120 \mu \mathrm{s}$. There is a dip of about 


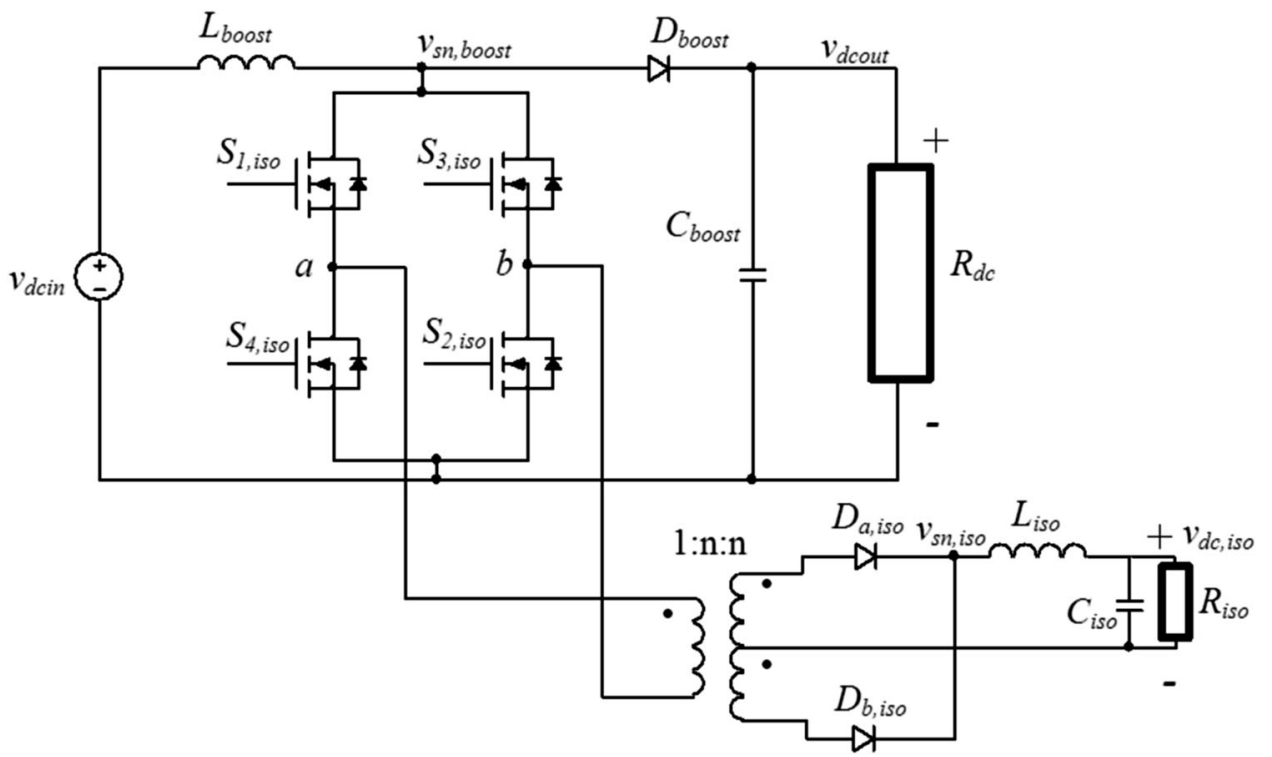

Figure 21. Integrated isolated dual-output converter.

$175 \mathrm{mV}$ for this load step event. Figure $17 \mathrm{~b}$ shows that the step-down output $\left(v_{o 2}\right)$ follows the reference from 4 to $6 \mathrm{~V}$. The step-up output is regulated to its predefined value of $18 \mathrm{~V}$ during this event.

An IDOC-based nanogrid has been readily built using off-the-shelf components and commercially available loads in local market to show its ready usability in a rural electrification application. Figure 18 shows the block diagram of the nanogrid along with some typical rural loads. In this scenario, the interconnect bus is associated with storage bus at $24 \mathrm{~V}$ dc. The input voltage is at $36 \mathrm{~V}$ dc to emulate a solar panel, which is used by the IDOC to generate a $120 \mathrm{~V}$ $\mathrm{dc}$ and a $24 \mathrm{~V} \mathrm{dc}$ interconnect bus output. The crossregulation of the IDOC of the converter is tested as follows. While all the other loads are kept on, a CFL lamp is turned off and its impact on the output voltages are observed. The result is shown in figure 19. It can be seen that there is a minimal impact on the rest of the system, indicating excellent cross-regulation property of the converter based on integrated architecture. A picture of the IDOC-based nanogrid in operation is shown in figure 20 .

\subsection{Other topology extensions derived from the boost converter utilizing the switched- boost action}

Isolated multi-port dc-dc converter topologies can be synthesized by interfacing the isolated voltage-fed converter topologies at the switch node of the boost converter topology. The full-bridge isolated buck converter topology has been interfaced at the switch node of the boost converter to obtain the integrated isolated dualoutput converter topology (see figure 21) [11]. Analysis of the converter shows that the behaviour is similar to that of boost and full-bridge isolated buck converter topology.

\section{Conclusion}

In this paper a review of dual-output converter topologies has been made. These topologies have been synthesized by interfacing a voltage-fed converter topology at the switch node of the boost converter. The fundamental principle behind the operation of the converters is the switched-boost action. This phenomenon has been illustrated in this paper. Three case studies have been presented in order to illustrate the proposed circuit behaviour.

\section{References}

[1] Boroyevich D, Cvetkovic I, Dong D, Burgos R, Wang F and Lee F 2010 Future electronic power distribution systems-a contemplative view. In: Proceedings of the 12th International Conference on Optimization Electrical and Electronic Equipment, OPTIM 2010, Brasov, Romania, May 20-22, pp. 1369-1380

[2] Shamsi P and Fahimi B 2013 Dynamic behavior of multiport power electronic interface under source/load disturbances. IEEE Trans. Ind. Electron. 60(10): 4500-4511

[3] Rodriguez M, Stahl G, Corradini L and Maksimovic D 2013 Smart DC power management system based on softwareconfigurable power modules. IEEE Trans. Power Electron. 28(4): $1571-1586$ 
[4] Adda R, Ray O, Mishra S and Joshi A 2013 Synchronous reference frame based control of switched boost inverter for standalone DC nanogrid applications. IEEE Trans. Power Electron. 28(3): 1219-1233

[5] Erickson R W and Maksimovic D 2001 Fundamentals of power electronics, 2 nd edn. Norwell: Kluwer

[6] Mishra S, Adda R and Joshi A 2012 Inverse WatkinsJohnson topology based inverter. IEEE Trans. Power Electron. 27: 1066-1070

[7] Ray O and Mishra S 2014 Boost-derived hybrid converter with simultaneous DC and AC outputs. IEEE Trans. Ind. Appl. 50(2): 1082-1093
[8] Adda R, Mishra S and Joshi A 2013 Analysis and PWM control of switched boost inverter. IEEE Trans. Ind. Electron. 60: 5593-5602

[9] Mishra S and Ray O 2013 Advances in nanogrid technology and its integration into rural electrification in India. In: Proceedings of IEEE IPEC, Hiroshima, Japan, March 2013, pp. 2707-2713

[10] Ray O, Prasad A, Mishra S and Joshi A 2015 Integrated dual output converter. IEEE Trans. Ind. Electron. 62(1): 371-382

[11] Ray O and Mishra S 2013 A multi-port converter topology with simultaneous isolated and non-isolated outputs. In: Proceedings of IEEE IECON, Vienna, Austria, October 2013, pp. 7118-7123 